\title{
Synthesis of tetracalcium phosphate at reduced temperatures
}

\author{
Karlis Agris Gross ${ }^{a}$, Elina Rozite ${ }^{b}$ \\ Institute of Biomaterials and Biomechanics, Riga Technical University, Latvia \\ akgross@rtu.Iv, ${ }^{b}$ roziteelina@inbox.Iv
}

Keywords: tetracalcium phosphate, oxyapatite, solid-state synthesis, hydroxyapatite bone cement.

\begin{abstract}
Tetracalcium phosphate (TTCP) requires the highest synthesis temperatures of all the calcium phosphates, but now a new process is available at $400{ }^{\circ} \mathrm{C}$ lower than previously, at $900{ }^{\circ} \mathrm{C}$. Instead of ball-milling reactants for a homogeneous mix, the reactants for solid-state synthesis were assembled in an amorphous phase. Heating produced hydroxyapatite, then oxyapatite and finally TTCP. Amorphous nanoparticles were synthesized and then heated in air or in vacuo. The sequence of solid-state reactions were tracked with X-ray diffraction and Fourier transform infra-red spectroscopy. Heating in air stabilized the carbonate containing apatite, thereby requiring higher temperatures for decomposition, as per previous studies. Heating in vacuum promoted oxyapatite; a critical step for reaction with calcium oxide to generate TTCP. This faster process enables production at a lower temperature and minimizes ball milling for producing fine TTCP powders.
\end{abstract}

\section{Introduction}

Of all the calcium phosphates, tetracalcium phosphate (TTCP) requires the highest temperatures and longest synthesis time to produce a pure phase. This difficulty in manufacture limits the availability of the most alkaline calcium phosphate and restricts wider exploration for calcium phosphate cements. Previous attempts have reduced the synthesis temperature to $1200{ }^{\circ} \mathrm{C}$, but pure TTCP still relies on processing at $1300{ }^{\circ} \mathrm{C}$ [1]. This work will explain the new method that has fewer processing stages and enables faster TTCP production at a lower temperature.

Two developments have reduced the processing temperature. The first involves ball-milling to prepare finer particles in a well-blended powder for heating at higher temperatures. This homogeneous blend has placed reacting particles within closer proximity of each other to achieve the desired TTCP, while finer particles have reduced the diffusion time: providing a shorter heating time at $1500{ }^{\circ} \mathrm{C}$ from $24 \mathrm{~h}$ [2] to $6 \mathrm{hrs}$ [3] followed by a reduction in temperature $1300{ }^{\circ} \mathrm{C}$ [4]. The second development has used an ammonium hydrogen phosphate reactant instead of a calcium phosphate that provides a separate phosphate reactant for easier diffusion with the calcium oxide to produce TTCP. This has further reduced the reaction temperature to $1250{ }^{\circ} \mathrm{C}$ [4]. Regardless, in both cases the reaction in air at high temperatures evolves intermediate calcium phosphates before generation of TTCP (Apatite is usually the intermediate phase, and when thermally destabilized manifests tricalcium phosphate and tetracalcium phosphate). A homogeneous mix has been provided at the particle level, but mixing at the atomic level may be possible at an earlier stage.

Another strategy uses a cue from nature to produce calcium phosphate - the use of an amorphous phase intermediate with the required chemistry. In previous work, the reactants included crystalline forms: the calcium originated from $\mathrm{CaCO}_{3}$, but phosphorus was sourced from a calcium phosphate $\left(\mathrm{CaHPO}_{4}[5]\right.$ or $\mathrm{Ca}_{2} \mathrm{P}_{2} \mathrm{O}_{9}$ [1] $)$ or a more easily decomposed additive $\left(\mathrm{NH}_{4}\right)_{2} \mathrm{HPO}_{4}$ [4]. Milling has a lower limit for the smallest particle size. The unit size of each crystalline phase provides the smallest reactant size for solid-state diffusion to TTCP. A different approach homogenizes chemical species at the atomic level that may be possible in an amorphous phase. Both calcium phosphate and calcium carbonate may exist in the amorphous state: the analogy to a well-mixed solution except in the solid state. The chemical species requiring a charge balance in the amorphous state could be positioned in the required proximity to crystallize into TTCP, and so lower the diffusion distance to establish the required stoichiometry at the nanometer level. 
The processing atmosphere must support the formation of TTCP. Tetracalcium phosphate is free of hydroxyl groups and so processing would ideally be conducted in a moisture-free environment. Brown et al [2] heated reactants in a vacuum furnace, and although not specified, applied conditions to increase the chances of successfully producing TTCP. All other studies report the use of a conventional furnace [6]. This work will investigate the effects of heating in air and vacuum at different temperatures to see whether the atmosphere influences the ability to form TTCP. Isochronal studies will then reveal phase development at higher temperatures.

The objective is to investigate whether it is possible to produce TTCP from an amorphous phase an amorphous starting phase for a more homogeneous mix of reactants and investigate the processing atmosphere necessary in produce TTCP. Both the conventional approach of heating in air will be compared to heating in vacuum to see the effect of a moisture free environment on TTCP purity.

\section{Materials and Methods}

Synthesis of reactants. An amorphous phase was synthesized by mixing a calcium nitrate tetrahydrate solution into an ammonium hydrogen phosphate and ammonium carbonate containing solution to establish the $\mathrm{Ca} / \mathrm{P}$ molar ratio of 2 . The suspension was mixed for 10 minutes, filtered, rinsed with deionized water, filtered and then treated with ethanol before oven drying. The synthesized powder was characterized by $\mathrm{X}$-ray diffraction and pressed into a tablet with $\mathrm{KBr}$ for analysis of bonding by Fourier transform infra-red spectroscopy.

Solid-state synthesis. The synthesized powder was heated in a cylindrical furnace in air or in vacuum at different temperatures for 1 hour. Heating involved a heating rate of $5{ }^{\circ} \mathrm{C} / \mathrm{min}$ to the maximum temperature and a holding time of $1 \mathrm{~h}$. For powder heated in air, the ceramic crucible was removed from the furnace for cooling in air. For powder heated in vacuum, the cylindrical furnace was withdrawn from the custom-made quartz glass arrangement for cooling in air.

Characterization and analysis. Powder was analyzed with X-ray diffraction to identify the phase evolution upon heating and also to follow the solid-state reactions in the formation of tetracalcium phosphate. Analysis was carried out with a D8 ADVANCE diffractometer (Bruker). Diffraction patterns were recorded from $5^{\circ}$ to $60^{\circ}$ using $\mathrm{Cu} \mathrm{K \alpha}$ radiation $(\lambda=1.54 \AA$ generated at $40 \mathrm{~mA}$ and 40 $\mathrm{kV}$ ) at a $0.2^{\circ}$ step size.

The same powders were analyzed with Fourier transform infra-red spectroscopy to identify the bonding and follow the hydroxyl and carbonate bonding in the powder. An FTIR spectrophotometer (Frontier, Perkin Elmer, USA) collected the spectrum at a $4 \mathrm{~cm}^{-1}$ resolution between 4000 and 450 $\mathrm{cm}^{-1}$. Powder pre-ground in a mortar and pestle was uniformly distributed in $300 \mathrm{mg}$ of $\mathrm{KBr}$ powder and compressed to form a $\mathrm{KBr}$ tablet.

\section{Results and Discussions}

Synthesis of the precipitate produced an amorphous phase, as shown by the broad peak in the Xray diffraction pattern, Fig 1 . The absence of crystalline peaks suggested an amorphous phase for both the calcium and phosphate groups. No further information could be provided about the distribution of elements based on the X-ray diffraction pattern. 


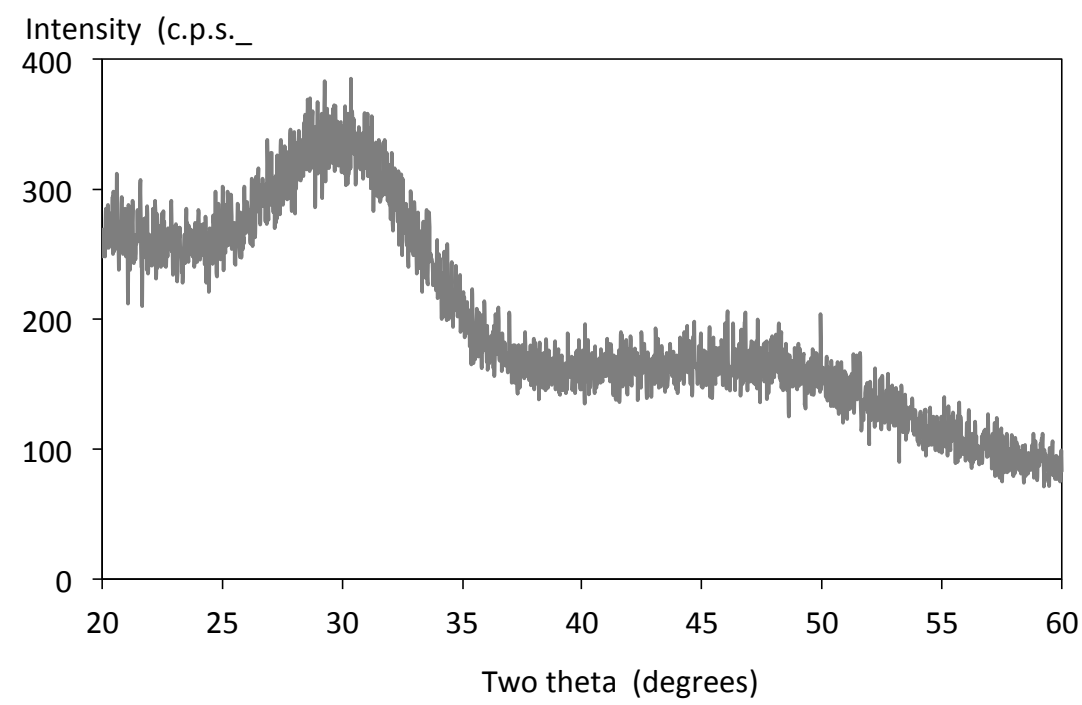

Figure 1. X-ray diffraction of synthesized powder showing an amorphous phase.

Heating the amorphous phase in air displayed fewer phases compared to the conventional process for making TTCP. At $800{ }^{\circ} \mathrm{C}$, only apatite was noted in the X-ray diffraction pattern, Fig 2. At $900{ }^{\circ} \mathrm{C}, \mathrm{CaO}$ appeared as seen by the small peak at $37.1^{\circ}$. Heating to $1100{ }^{\circ} \mathrm{C}$ showed more $\mathrm{CaO}$, but there is no sign of TTCP formation. The FTIR absorption peak at $871 \mathrm{~cm}^{-1}$ suggested the formation of carbonated apatite at $800{ }^{\circ} \mathrm{C}$ and $900{ }^{\circ} \mathrm{C}$, Fig 2. The resulting phases were thus carbonated apatite and calcium oxide that could react further to form tetracalcium phosphate. Previous processes formed an apatite, calcium oxide and other phases after the decomposition of reactant phases. As a result, this new process made it easier to follow the initial stages at lower temperatures. Higher temperatures are required for the next stage - decomposition of apatite.

Heating in vacuum accelerated the phase transitions. Heating at $700{ }^{\circ} \mathrm{C}$ produced an apatite phase, but the $2^{\text {nd }}$ most intense apatite X-ray peak, on the right of the major XRD peak, is more intense and suggests a modification in the apatite lattice - possibly from the additional calcium and carbonate, Fig 3.
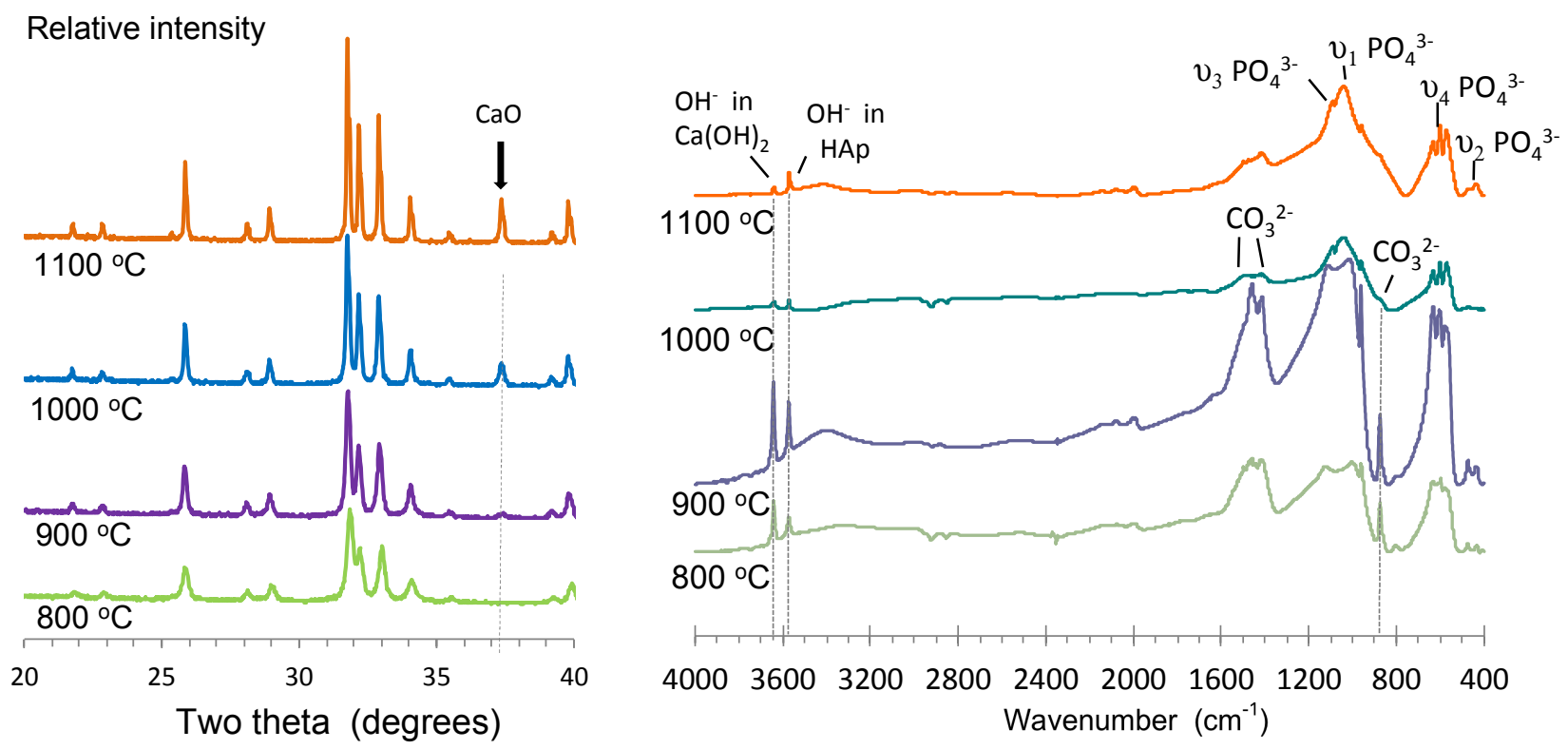

Figure 2. X-ray diffraction patterns and Fourier transform infra-red spectra of powders after heating for 1 hour in air at $800{ }^{\circ} \mathrm{C}, 900{ }^{\circ} \mathrm{C}, 1000{ }^{\circ} \mathrm{C}$ and $1100{ }^{\circ} \mathrm{C}$, showing evolution of $\mathrm{CaO}$ above $900{ }^{\circ} \mathrm{C}$. 
After heating at $800{ }^{\circ} \mathrm{C}$ in vacuum, two new peaks at $25.4^{\circ}$ and $29.6^{\circ}$ show the first signs of TTCP (see triangular symbols in the XRD pattern at $800{ }^{\circ} \mathrm{C}$, Fig 3), without any trace of $\mathrm{CaO}$. At $900{ }^{\circ} \mathrm{C}$, the TTCP peaks are well established, and a broad peak at $37.1^{\circ}$ reveals fine $\mathrm{CaO}$ crystallites. The FTIR spectra show less carbonate, more $\mathrm{CaO}$ (inferred from the intense $\mathrm{Ca}(\mathrm{OH})_{2}$ peak formed from the reaction between $\mathrm{CaO}$ and water) and structural water within the apatite lattice, Fig 3. The further reaction between $\mathrm{CaO}$ and oxyapatite is slowed due to the slower hydroxyl ion removal from hydroxylapatite; a critical step before reaction between oxyapatite and $\mathrm{CaO}$. As a result, a store of $\mathrm{CaO}$ is established in readiness for reaction with oxyapatite. At $1000{ }^{\circ} \mathrm{C}$, tetracalcium phosphate has totally formed, as seen by the absence of apatite peaks in the XRD pattern, and the absence of hydroxyl peaks at $630 \mathrm{~cm}^{-1}$ and $3570 \mathrm{~cm}^{-1}$ in the FTIR spectra.

The influence of the heating atmosphere is best seen by collating information from the XRD pattern and FTIR spectra of powders heated in air and in vacuum, Fig 4. Since the apatite structure is similar to the TTCP structure [7], the fastest means to determine complete transformation is take the ratio of the most intense TTCP peak with the peak at $31.9^{\circ}$, that will be more intense if apatite is present, from the major apatite peak at $31.8^{\circ}$. Complementary evidence of TTCP can be seen from FTIR spectra in the serrated phosphate absorption peaks [3] and the absence of hydroxyl peaks, that would otherwise enrich the spectra if hydroxylapatite was present. The purity of tetracalcium phsphate needs to be further investigated by Rietveld analysis.

Absence of moisture during heating promotes oxyapatite formation and further reaction to TTCP. The atmosphere plays a more critical role than temperature in the reaction kinetics of TTCP formaton, Fig 4. The reaction proceeds by decomposition of calcium carbonate to $\mathrm{CaO}$ that reacts with oxyapatite to produce TTCP. Very small XRD peaks show the first signs of TTCP at $800{ }^{\circ} \mathrm{C}$ after heating in vacuum, Fig 3 . The small raised background, after heating at $700{ }^{\circ} \mathrm{C}$, may represent the additive effect of the two most intense TTCP peaks that initially appear very broad due to the nanosize effect. The next stage of TTCP synthesis is determined by the availability of both $\mathrm{CaO}$ and oxyapatite. The rate determining step appears to be formation of oxyapatite, since this is generated slower than $\mathrm{CaO}$.
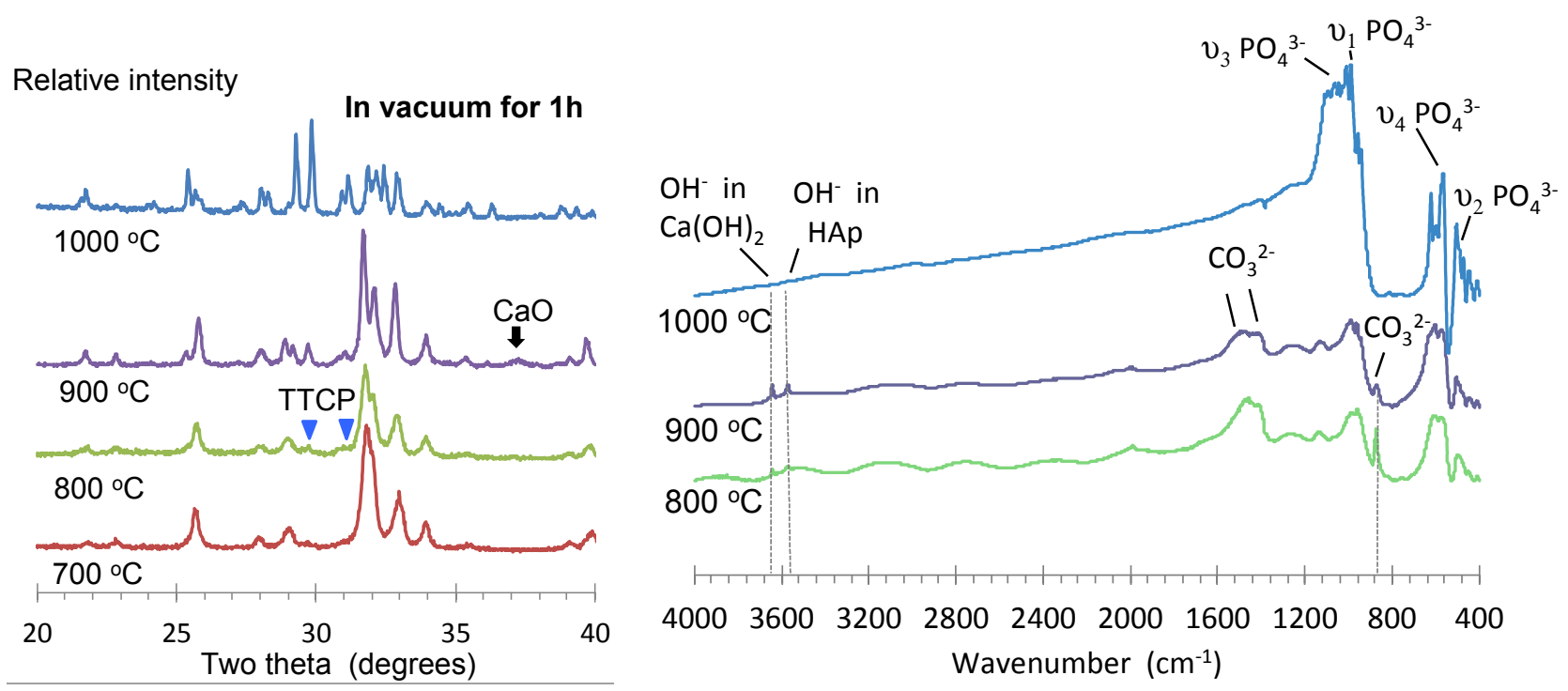

Figure 3. XRD and FTIR of powders heated in vacuum for 1 hour at $700{ }^{\circ} \mathrm{C}$ to $1000{ }^{\circ} \mathrm{C}$. The first sign of TTCP can be seen at $800{ }^{\circ} \mathrm{C}$ in the XRD pattern by the peaks marked with triangles, but $\mathrm{CaO}$ is first observed at $900{ }^{\circ} \mathrm{C}$, shown with an arrow. 


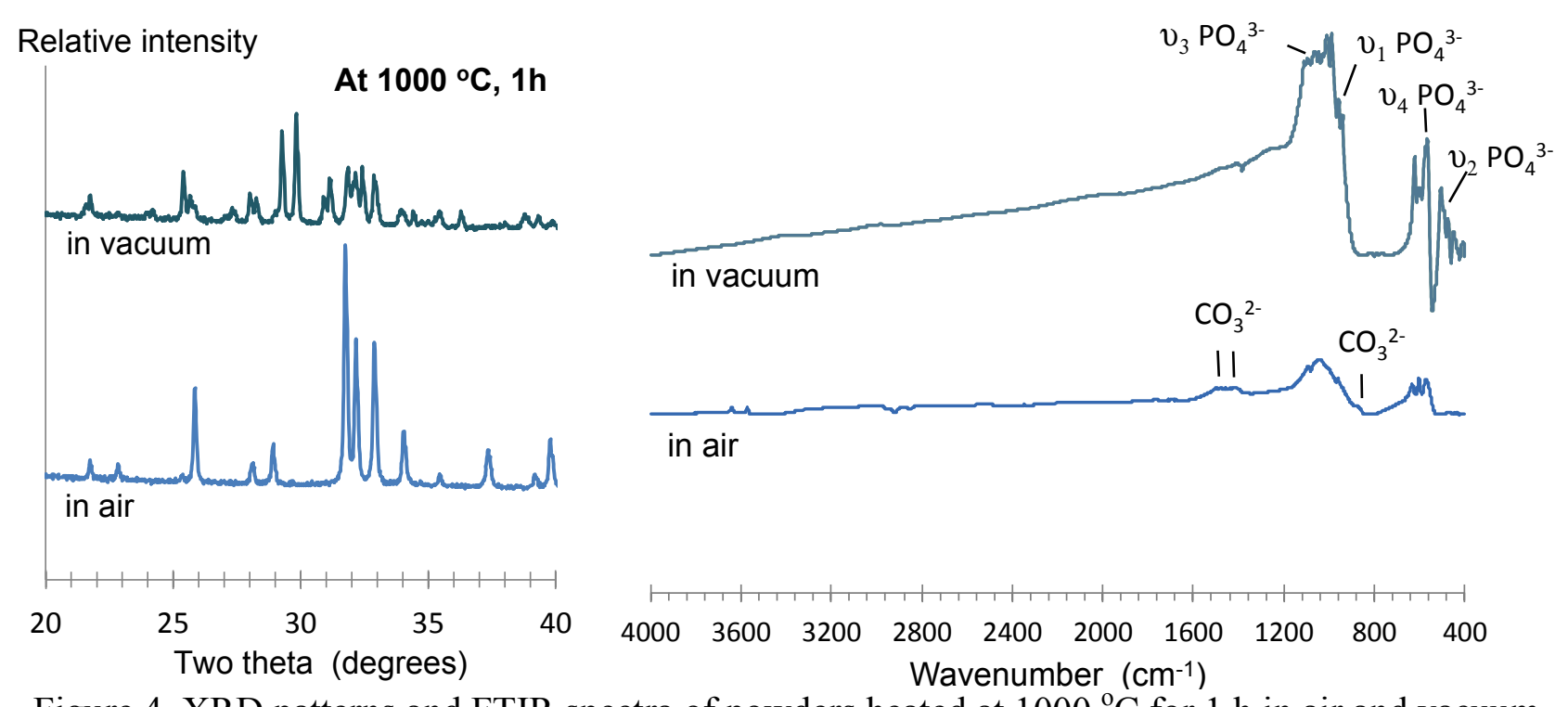

For producing TTCP, reacting oxyapatite with $\mathrm{CaO}$ is simpler than the previously used approach. The previous approach (Route 1 in Fig 5) used higher temperatures to force dehydroxylation of hydroxyapatite, and decomposed hydroxyapatite to TTCP and TCP. The TCP then reacted with $\mathrm{CaO}$ to generate TTCP. Higher temperatures create larger grains, and the decomposition separates TCP grains from $\mathrm{CaO}$ grains; both effects place a greater requirement for more diffusion to complete the solid state synthesis to TTCP. Route 2 involves only two reacting components, that at a smaller size require less time to complete the reaction to TTCP.

Particle characteristics will vary with the processing route, Table 1 . Route 1 , due to the higher temperatures, will produce larger particles that through sintering at higher temperatures become more bonded. Separation of the sintered particles by ball milling generates angular particles. The TTCP generated from the initial decomposition coupled with TTCP from the reaction between TCP and $\mathrm{CaO}$ is likely to result in a bimodal TTCP crystallite size. In contrast, Route 2 at a lower processing temperature will retain smaller particles with a narrower crystallite size range. Particles will be more rounded and more separated.

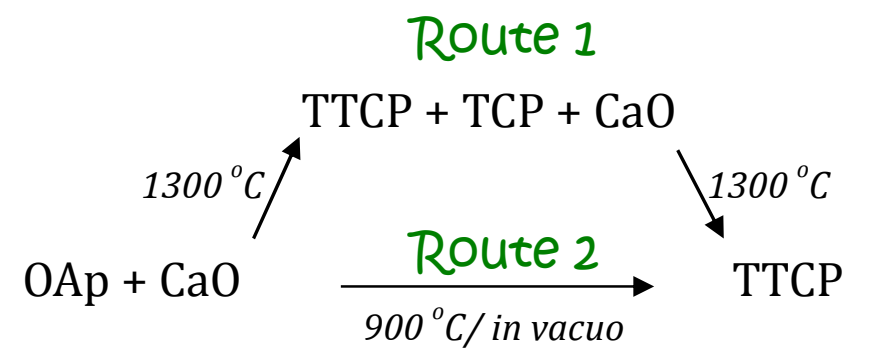

Figure 5. Two routes for synthesizing TTCP, showing the traditional higher temperature pathway that decomposes apatite (Route 1) and the new low temperature route via oxyapatite without decomposition (Route 2).

The new process involves fewer steps allowing the synthesis to be completed at a lower temperature and a shorter time, Table 1. More favourable conditions for processing - a lower temperature and short time - lead to more desirable characteristics for exploration in bone cements.

Table 1. A comparison of particle characteristics and processing from the two production routes.

\begin{tabular}{|l|l|l|}
\hline Characteristics & Route 1 & Route 2 \\
\hline Particle size & large & smaller \\
\hline Particle shape & angular & rounded \\
\hline Particle bonding & large & small \\
\hline Crystallite size & variable & small \\
\hline
\end{tabular}

\begin{tabular}{|l|l|l|}
\hline Processing & Route 1 & Route 2 \\
\hline \# steps & many & few \\
\hline Time & long & short \\
\hline Lowest temp. & $1300{ }^{\circ} \mathrm{C}$ & $900^{\circ} \mathrm{C}$ \\
\hline
\end{tabular}


It is expected that TTCP from the smaller grain size has promise for increased reactivity in application to calcium phosphate cements.

\section{Summary}

A new synthesis process used a homogeneous mix of reactants that upon heating formed apatite, then oxyapatite and then generated a tetracalcium phosphate as low as $800^{\circ} \mathrm{C}$. This pathway differs from the previous route where hydroxyapatite decomposed and then by interdiffusion generated tetracalcium phosphate closer to $1300{ }^{\circ} \mathrm{C}$. The heating atmosphere plays a crucial role, supporting transformation in vacuum, but maintaining an apatite phase in air. This new process is faster, occurs at a lower temperature, with fewer intermediate steps supporting a smaller particle size tetracalcium phosphate.

\section{Acknowledgements}

The authors acknowledge Arnolds Ubelis for designing the vacuum system and Aleksandrs Kapralovs at the Atomic Spectroscopy Institute for quartz glass blowing the tailor-made vacuum system. The Faculty of Chemistry at Uni of Latvia provided access to X-ray diffraction and Fourier transform infra-red spectroscopy. This project follows the theme of alternative processing methods in the Refined Step project PIRSES-2013-612691.

\section{References}

[1] Monma H, Goto M, Nakajima H, Hashimoto H. Preparation of tetracalcium phosphate. Gypsum and Lime 1986;202:17-21.

[2] Brown WE, Epstein EF. Crystallography of tetracalcium phosphate. J Res Nat Bur Stand -A Phys Chem 1965;69A:547-51.

[3] Posset U, Locklin E, Thull R, Kiefer W. Vibrational spectroscopic study of tetracalcium phosphate in pure polycrystalline form and as a constituent of a self-setting bone cement. J Biomed Mater Res 1998;40:640-5.

[4] Sargin Y, Kizilyalli M, Telli C, Guler H. A new method for the solid-state synthesis of tetracalcium phosphate, a dental cement: X-ray powder diffraction and IR studies. J Europ Ceram Soc 1997; 17:963-70.

[5] Ciesla K, Rudnicki R. Synthesis and transformation of tetracalcium phosphate in solid-state. 1. Synthesis of roentgenographically pure tetracalcium phoshate from calcium dibasic phosphate and calcite. Polish J Chem 1987;61:719-27.

[6] Guo $\mathrm{D}, \mathrm{Xu} \mathrm{K}$, Han Y. Influence of cooling modes on purity of solid-state synthesized tetracalcium phosphate. Mater Sci Eng B 2005;116:175-81.

[7] Dickens B, Brown WE, Kruger GJ, Stewart JM. Tetracalcium phosphate: Crystal structure and relationship to $\left.\mathrm{Ca}_{5}\left(\mathrm{PO}_{4}\right)_{3}\right) \mathrm{OH}$ and $\mathrm{K}_{3} \mathrm{Na}\left(\mathrm{SO}_{4}\right)_{2}$. Acta Cryst 1973;29:2046-56. 


\section{Bioceramics Volume 26}

10.4028/www.scientific.net/KEM.631

\section{Synthesis of Tetracalcium Phosphate at Reduced Temperatures}

10.4028/www.scientific.net/KEM.631.93

\section{DOI References}

[3] Posset U, Locklin E, Thull R, Kiefer W. Vibrational spectroscopic study of tetracalcium phosphate in pure polycrystalline form and as a constituent of a self-setting bone cement. J Biomed Mater Res 1998; 40: 640-5. http://dx.doi.org/10.1002/(SICI)1097-4636(19980615)40:4\&1t;640::AID-JBM16\&gt;3.0.CO;2-J [4] Sargin Y, Kizilyalli M, Telli C, Guler H. A new method for the solid-state synthesis of tetracalcium phosphate, a dental cement: X-ray powder diffraction and IR studies. J Europ Ceram Soc 1997; 17: 963-70. http://dx.doi.org/10.1016/S0955-2219(96)00196-3

[6] Guo D, Xu K, Han Y. Influence of cooling modes on purity of solid-state synthesized tetracalcium phosphate. Mater Sci Eng B 2005; 116: 175-81. http://dx.doi.org/10.1016/j.mseb.2004.09.032

[7] Dickens B, Brown WE, Kruger GJ, Stewart JM. Tetracalcium phosphate: Crystal structure and relationship to $\mathrm{Ca} 5(\mathrm{PO} 4) 3) \mathrm{OH}$ and $\mathrm{K} 3 \mathrm{Na}(\mathrm{SO} 4) 2$. Acta Cryst 1973; 29: 2046-56.

http://dx.doi.org/10.1107/S0567740873006102 